\title{
A Ocorrência de hidratos de gás no Cone do Rio Grande, Bacia de Pelotas
}

Jose Antonio Cupertino - Instituto do Petróleo e dos Recursos Naturais -IPR/PUCRS

Copyright 2021, SBGf - Sociedade Brasileira de Geofísica.

This paper was prepared for presentation during the $17^{\text {th }}$ International Congress of the Brazilian Geophysical Society held in Rio de Janeiro, Brazil, 8-11 November 2021

Contents of this paper were reviewed by the Technical Committee of the $17^{\text {th }}$ International Congress of the Brazilian Geophysical Society and do not necessarily represent any position of the SBGf, its officers or members. Electronic reproduction or storage of any part of this paper for commercial purposes without the written consent of the Brazilian Geophysical Society is prohibited.

\section{Resumo}

A Bacia de Pelotas, uma extensa área sedimentar na porção meridional da margem leste brasileira, tem sido alvo de sucessivas campanhas visando entender importância de acumulações com hidratos de gás (HG) na região do Cone do Rio Grande (CRG). No CRG ocorre uma espessa sequência sedimentar depositada durante o Neógeno onde, em linhas sísmicas, é identificado um refletor sísmico de alta impedância e polaridade inversa em relação do fundo marinho denominado Bottom Simulating Reflector (BSR). Este horizonte está intimamente associado à definição da base da chamada Zona de Estabilidade do Gás Hidrato (ZEGH). Assim, a partir de 2010, o Instituto do Petróleo e dos Recursos Naturais (IPR) da PUCRS iniciou uma série de estudos específicos visando o entendimento da gênese e potencialidade deste recurso energético que resultaram na primeira amostragem de hidratos de gás no país, na identificação de comunidades quimiossintéticas associadas ao vazamento de gás no fundo marinho e na identificação de plumas de gás na coluna d'água. Para tanto foram efetuadas sete campanhas oceanográficas para coleta de dados geofísicos, amostragem de rochas (piston cores) e coleta de fluidos.

Os resultados estão apresentados em diversos artigos científicos publicados que despertaram o interesse da comunidade científica internacional, pois, embora as pesquisas tenham avançado significantemente, as amostragens ainda restritas aos horizontes mais superficiais (estão disponíveis por amostragem da piston cores de no máximo $60 \mathrm{~m}$ de profundidade). Deste modo foi criado um projeto para a perfuração de poços com testemunhagem contínua com até $800 \mathrm{~m}$ de profundidade, no âmbito do International Ocean Discovery Program, a expedição "Ciclo do carbono em margens continentais com acumulações de metano: estudo de caso no Cone de Rio Grande. (IODP; Expedition 394 - Rio Grande Cone Methane and Carbon Cycling)".

Esta expedição, uma proposta conjunta entre as Universidades PUCRS (Instituto do Petróleo e dos Recursos Naturais), Columbia (EUA - Lamont-Doherty Earth Observatory) e Linnaeus (Suécia), tem o intuito de entender os processos biogeoquímicos e físicos relacionados com a geração e acumulação de metano em sedimentos, e o relacionamento do metano com a coluna d'água no tempo (transferência de massa, vazamentos no fundo marinho). Os diversos proponentes envolvidos irão desenvolver a análises das amostras coletadas a partir da perfuração de cinco poços ao longo de quatro diferentes sítios de interesse previamente identificados, quando serão recuperados em torno de $2.800 \mathrm{~m}$ de testemunhos dos sedimentos desta região.

Estão envolvidos pesquisadores de cinco instituições brasileiras, PUCRS, FURG, USP, UFRGS e Petrobrás. 